\title{
Portal Venous Pressure as a Predictor of Mortality in Child's A Cirrhotic Patients Undergoing Elective Surgery: A Prospective Study
}

\author{
Mohamed El-Ghobary ${ }^{1}$, Ahmed Abdallah Salman ${ }^{1 *}$, Hossam El-Din Shaaban², Mohamed Saber Mostafa ${ }^{2}$, \\ Mohamed Sabry Tourky ${ }^{4}$, Ossama Ramzy Youssef ${ }^{5}$, Mahmoud Gouda Omar ${ }^{1}$ \\ ${ }^{1}$ Department of Internal Medicine, Faculty of medicine, Cairo University, Cairo, Egypt; ${ }^{2}$ Department of Gastroenterology, National \\ Hepatology and Tropical Medicine Research Institute, Cairo, Egypt; ${ }^{3}$ Department of General Surgery, Faculty of Medicine, \\ Cairo University, Cairo, Egypt; ${ }^{4}$ Department of General Surgery, Alawi Tunsi Hospital, Mecca, Saudi Arabia; ${ }^{5}$ Department of \\ Anaesthesia and Intensive Care, Ain Shams University, Cairo, Egypt
}

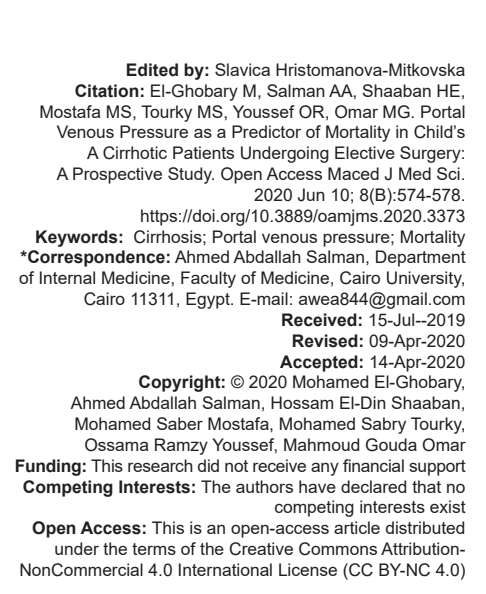

\section{Abstract}

BACKGROUND: Recently, portal venous pressure (PVP) exhibited high sensitivity and specificity in anticipating death in cirrhotic cases submitted to emergency operations.

AIM: The current prospective work aimed to evaluate the utility of PVP in predicting 1st month post-operative death in Child's A cirrhotic cases who underwent elective operations.

METHODS: One-hundred and twenty cirrhotic cases that were planned to undergo elective surgery were enrolled in the current prospective work. The intraoperative (I.O) PVP and central venous pressure (CVP) were measured. The statistical analysis was performed using the SPSS version 22.0. The receiver operative curve was plotted to measure the predictive value of PVP. Multivariate analysis was done using logistic regression method for the significant variables impacting mortality on univariate analysis

RESULTS: Twenty-nine patients died in the current work. Patients who survived had statistically considerably lower PVP than patients who died $(8.2 \pm 1.5$ vs. $12.5 \pm 1.6 \mathrm{mmHg}$, respectively, $p<0.001)$. Similarly, patients who died had significantly higher I.O CVP ( $<0.001)$, body mass index $(p<0.001)$, and were more likely to have model for end-stage liver disease score between 9 and $16(p=0.003)$. At a cutoff value $\geq 10.5 \mathrm{mmHg}$, the PVP had a sensitivity of $82.8 \%$ and specificity of $93.4 \%$ for the prediction of mortality. The logistic regression analysis showed that only PVP (odds ratio [OR] $=3.1,95 \%$ confidence interval $[\mathrm{Cl}] 1.25-7.5)$ and $\mathrm{CVP}(\mathrm{OR}=2.8,95 \% \mathrm{Cl} 1.2-6.5)$ were the only independent predictors of mortality.

CONCLUSION: PVP is a significant predictor of death in Child's A cirrhotic cases submitted to elective operations.

\section{Introduction}

Liver cirrhosis is a major public health burden that is characterized by progressive, usually irreversible, loss of normal hepatic architecture, and functions [1]. According to recent epidemiological figures, the prevalence of histological cirrhosis ranges from $4.5 \%$ to $9.5 \%$ of the global adults population and is responsible for more than 1 million deaths in 2010 [2], [3]. The condition can occur as the end stage of chronic liver diseases, mainly alcoholic liver disease and viral hepatitis, and frequently remain asymptomatic until the development of complications [4]. Cirrhosis is a leading cause of morbidity worldwide with increased risks of a wide range of complications. Patients with cirrhosis can develop hepatic encephalopathy, ascites, bleeding varices, spontaneous bacterial peritonitis, and hepatocellular carcinoma as a result of severe liver cirrhosis [5]. Cirrhosis is one of the main contributors to the global mortality rate. Despite the major advances in the management of many causes of cirrhosis, it is expected that cirrhosis-related mortality will be tripled by 2030 [6].
On the other hand, anesthesia and surgery in cirrhotic patients are associated with a significant increase in the risks of morbidity and mortality. The previous reports have shown that the rates of serious complications and death are significantly higher in cirrhotic patients undergoing surgery than the normal population [7]. The mortality rates in patients with well-compensated or occult cirrhosis, who underwent surgical procedures, were reported to be as high as $25 \%$ [8]. Therefore, proper pre-operative assessment is critical in cirrhotic patients to improve the post-operative outcomes [9]. Over the past few decades, various biomarkers and predictive models were proposed for the prediction of death in cirrhotic cases submitted to elective and urgent surgeries. Child-Turcotte-Pugh classification, model for end-stage liver disease (MELD) score, prothrombin time, and other risk factors exhibited a significant correlation with post-operative death in patients with end-stage liver disease [10], [11].

Elevated portal pressure is one of the main features of advanced liver cirrhosis. The condition is defined as an elevation in portal venous pressure (PVP) 
above $12 \mathrm{mmHg}$, or hepatic venous pressure gradient above $5 \mathrm{mmHg}$, as a result of increased intrahepatic vascular resistance [12]. Portal hypertension is the leading pathophysiological mechanism for many cirrhotic-related complications with increased mortality and morbidity. The previous reports showed that the elevation in PVP could significantly predict the development and severity of esophageal varices [13], post-operative liver function before liver surgery [14], and survival [15]. More recently, PVP exhibited high sensitivity and specificity in anticipating death in cases with end-stage liver disease, who underwent emergency surgery [16]. However, the predictive role of PVP in cirrhotic cases scheduled for elective procedures is still questionable.

Thus, we performed this prospective work to evaluate the utility of PVP in portending early postoperative death in Child's A cirrhotic cases submitted to elective surgery.

\section{Materials and Methods}

The manuscript of the present study was conducted guided by the criteria of the strengthening reporting of observational studies in epidemiology [17]. We emphasize that this work was consistent with the Declaration of Helsinki and applicable local regulatory rules.

\section{Work design and patients}

This prospective cohort work was performed from November 2016 to November 2018 at Cairo and Ain Shams University Hospitals. Adult cirrhotic patients (18-65 years old) who were planned to undergo elective procedures were enrolled. Cirrhosis was confirmed by a constellation of clinical, laboratory, and radiological diagnoses.

Patients with Child B or C liver cirrhosis, hepatic malignancy, pre-operative portal or mesenteric vein occlusion, or acute surgical emergency were not included in the study. Written informed approval was taken from every participant before the study's enrollment, and the study protocol acquired the confirmation of the responsible ethics and research board.

Body mass index (BMI) was determined as follows: The body weight divided by the square of the body height $\left(\mathrm{kg} / \mathrm{m}^{2}\right)$ [18].

Diabetes mellitus confirmation was done according to the American Diabetes Association guidelines (glycated hemoglobin "HbA1C" more than $6.5 \%$ or fasting blood glucose more than $126 \mathrm{mg} / \mathrm{dL}$ or $2 \mathrm{~h}$ plasma glucose more than $200 \mathrm{mg} / \mathrm{dL}$ after oral glucose tolerance test) [19]. Hypertension was confirmed if blood pressure was more than $140 / 90 \mathrm{mmHg}$ on three or more separate occasions [20].

\section{Study's procedures}

After detailed history taking and thorough physical examination, all included patients underwent routine preoperative laboratory work-up comprising complete blood count, bleeding profile, hepatic, and renal functions.

Intraoperatively, the rate of infusion of crystalloid during the procedure was modified depending on the hemodynamic preload (with central venous line inserted into the right internal jugular vein) and urine output. Packed red blood cells were given to keep the hematocrit, between $25 \%$ and $30 \%$. Fresh frozen plasma, cryoprecipitate, and platelets were infused to treat intraoperative (I.O) coagulopathy.

In addition, one measurement of the PVP was acquired at the start of the operation. The PVP was assessed intraoperatively through an 18-gauge catheter, which was placed into one of the large jejunal, ileal mesenteric tributaries, or the main inferior mesenteric vein. The other side was connected through an extensionarterial line to a pressure transducer. If attainable, both the main inferior mesenteric vein and one large mesenteric tributary pressure were measured, and the mean value was considered. The normal range for directly measured PVP values was considered to be $5-10 \mathrm{mmHg}$ [21]. A figure of eight suture was performed in case of continuous oozing from the puncture site despite a proper compression.

\section{Study's objectives}

The primary objective in this work was the sensitivity and specificity of the PVP for the prediction of post-operative $1^{\text {st }}$ month mortality. The secondary objectives were the association between other variables (age, gender, comorbidities, operation type, and MELD) and mortality.

\section{Statistical analysis}

Data registry and statistical analysis were carried out using the SPSS version 22.0. Frequency tables with percentages were used for categorical data. Mean and standard deviation (SD) or median (range) were used for the description of numerical data according to the normality of the data. The normality of the data was evaluated using Shapiro-Wilk Test. Tests of significance (Chi-square, Student's t-test, or Mann-Whitney's U-test) were used depending on the normality of the data. The receiver operative curve (ROC) was plotted to measure the predictive value of PVP. Multivariate analysis was performed using logistic regression method for the significant variables impacting mortality on univariate analysis. $p<0.05$ was considered statistically significant. 


\section{Results}

The current report enrolled 120 cirrhotic patients who underwent elective surgery. The mean age of the included cases was $52.12 \pm 6.1$ years, and most cases were male $(87.5 \%)$. The performed procedures were open splenectomy $(37.5 \%)$, open cholecystectomy $(33.3 \%)$, and colectomy $(29.2 \%)$. The most common cause of cirrhosis was hepatitis C $(75 \%)$ and $B(17.2 \%)$. Most of the patients (84.2\%) had a MELD score between 9 and 16. The pre-operative laboratory investigations showed unremarkable values. Table 1 demonstrates the demographic and clinical data of the study groups.

Table 1: The demographic and pre-operative data of the study groups

\begin{tabular}{|c|c|}
\hline Variables & Patients $(n=120)$ \\
\hline Male, no. (\%) & $105(87.5)$ \\
\hline Age (years), mean $\pm S D$ & $52.12 \pm 6.1$ \\
\hline BMI $\left(\mathrm{kg} / \mathrm{m}^{2}\right)$, mean $\pm \mathrm{SD}$ & $27.2 \pm 3.1$ \\
\hline Diabetes, no. (\%) & $79(65.8)$ \\
\hline Hypertension, no. (\%) & $95(79.2)$ \\
\hline \multicolumn{2}{|l|}{ Cause of cirrhosis, no. (\%) } \\
\hline $\mathrm{HCV}$ & $90(75)$ \\
\hline HBV & $17(14.2)$ \\
\hline Cryptogenic & $8(6.7)$ \\
\hline Others & $5(4.2)$ \\
\hline \multicolumn{2}{|l|}{ Operation, no. (\%) } \\
\hline Open cholecystectomy & $40(33.3)$ \\
\hline Open splenectomy & $45(37.5)$ \\
\hline Colectomy & $35(29.2)$ \\
\hline \multicolumn{2}{|l|}{ MELD, no. (\%) } \\
\hline$\leq 8$ & $19(15.8)$ \\
\hline $9-16$ & $101(84.2)$ \\
\hline Hemoglobin $(\mathrm{g} / \mathrm{dL})$, mean $\pm \mathrm{SD}$ & $10.8 \pm 1.2$ \\
\hline TLC $\times 1000($ cell/mm²), mean \pm SD & $6.8 \pm 1.9$ \\
\hline Platelet, mean \pm SD & $219.9 \pm 80.9$ \\
\hline CRP (mg/dL), median (range) & $6(6-24)$ \\
\hline $\mathrm{INR}$, mean $\pm \mathrm{SD}$ & $1.2 \pm 0.1$ \\
\hline Bilirubin $(\mathrm{mg} / \mathrm{dL})$, mean $\pm \mathrm{SD}$ & $1.3 \pm 0.3$ \\
\hline AST (IU/L), median (range) & $40.5(16-78)$ \\
\hline ALT (IU/L), median (range) & $42(15-56)$ \\
\hline ALP (IU/L), median (range) & $114(67-298)$ \\
\hline GGT(IU/L), median (range) & $119.5(55-311)$ \\
\hline Bilirubin $(\mathrm{g} / \mathrm{dL})$, mean $\pm \mathrm{SD}$ & $3.6 \pm 0.3$ \\
\hline
\end{tabular}

Twenty-nine patients $(24.2 \%)$ died in the present study. Causes of mortality included sepsis in $13(10.8 \%)$ patients, hepatic decompensation in 7 (5.9\%) patients, myocardial infarction in $6(5 \%)$ patients, and pulmonary embolism in $3(2.5 \%)$ patients.

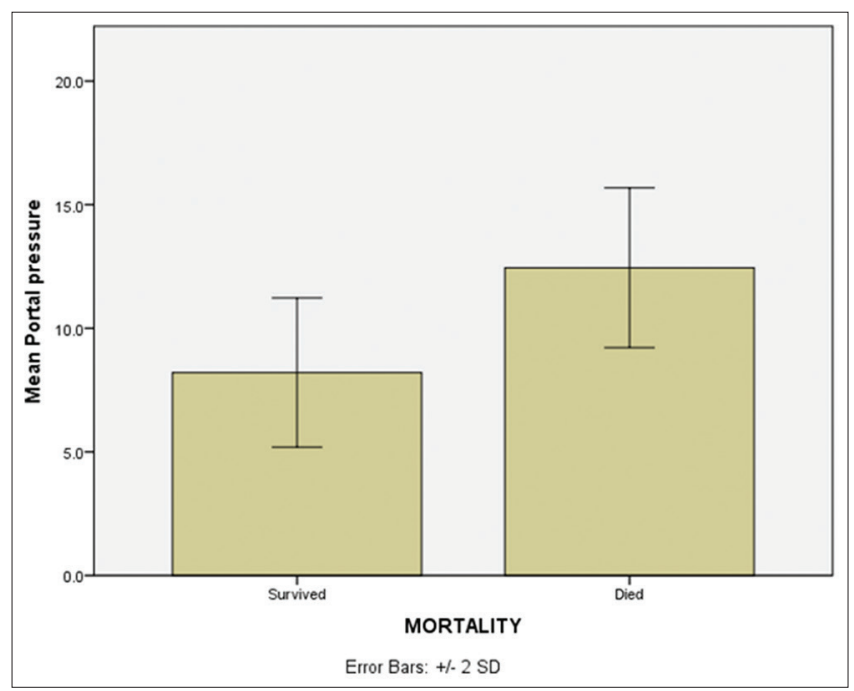

Figure 1: The distribution of portal venous pressure according to mortality
Patients who survived had a statistically significant lower PVP than patients who died $(8.2 \pm 1.5$ vs. $12.5 \pm 1.6 \mathrm{mmHg}$, respectively, $\mathrm{p}<$ 0.001 ; Figure 1). Similarly, patients who died had significantly higher IO central venous pressure (CVP) $(p<0.001)$, BMI $(p<0.001)$, and were more likely to have MELD score between 9 and $16(p=0.003)$. In contrast, there were no statistically significant associations between mortality and other clinical variables (Table 2).

Table 2: The association between mortality rate and study's variables

\begin{tabular}{|c|c|c|c|}
\hline Variables & Non-survivors $(n=29)$ & Survivors $(n=91)$ & $p$-value \\
\hline Male, no. (\%) & $26(89.7)$ & $79(86.8)$ & 0.485 \\
\hline Age (years), mean $\pm S D$ & $52.3 \pm 5.3$ & $51.9 \pm 6.4$ & 0.68 \\
\hline BMI $\left(\mathrm{kg} / \mathrm{m}^{2}\right)$, mean $\pm \mathrm{SD}$ & $29.3 \pm 2.1$ & $26.5 \pm 3.1$ & $<0.001^{* \star}$ \\
\hline Diabetes, no. (\%) & $19(65.5)$ & $60(65.9)$ & 0.56 \\
\hline Hypertension, no. (\%) & $25(86.2)$ & $70(76.9)$ & 0.21 \\
\hline \multicolumn{4}{|l|}{ Operation, no. (\%) } \\
\hline Open splenectomy & $10(34.5)$ & $35(38.4)$ & 0.43 \\
\hline Colectomy & $9(31)$ & $26(28.6)$ & \\
\hline \multirow{2}{*}{\multicolumn{4}{|c|}{ MELD, no. (\%) }} \\
\hline & & & \\
\hline$\leq 8$ & 0 & 19 (20.9) & $0.003^{*}$ \\
\hline $9-16$ & $29(100)$ & 72 (79.1) & \\
\hline PVP $(\mathrm{mmHg})$, mean & $12.5 \pm 1.6$ & $8.2 \pm 1.5$ & $<0.001^{* *}$ \\
\hline $\begin{array}{l} \pm \mathrm{SD} \\
\mathrm{CVP}(\mathrm{mmHg}), \text { mean } \\
\pm \mathrm{SD}\end{array}$ & $12.6 \pm 1.9$ & $8.3 \pm 1.7$ & $<0.001^{* *}$ \\
\hline
\end{tabular}

${ }^{*} \mathrm{p}<0.05$ significant, ${ }^{* *} \mathrm{p}<0.001$ highly significant. BMI: Body mass index, MELD: Model for end-stage liver disease, PVP. Portal venous pressure, CVP. Central venous pressure.

The ROC showed that the PVP was a significant discriminator of the occurrence of death with an area under the curve of 0.971 ( $p=0.001$; Figure 2). At a

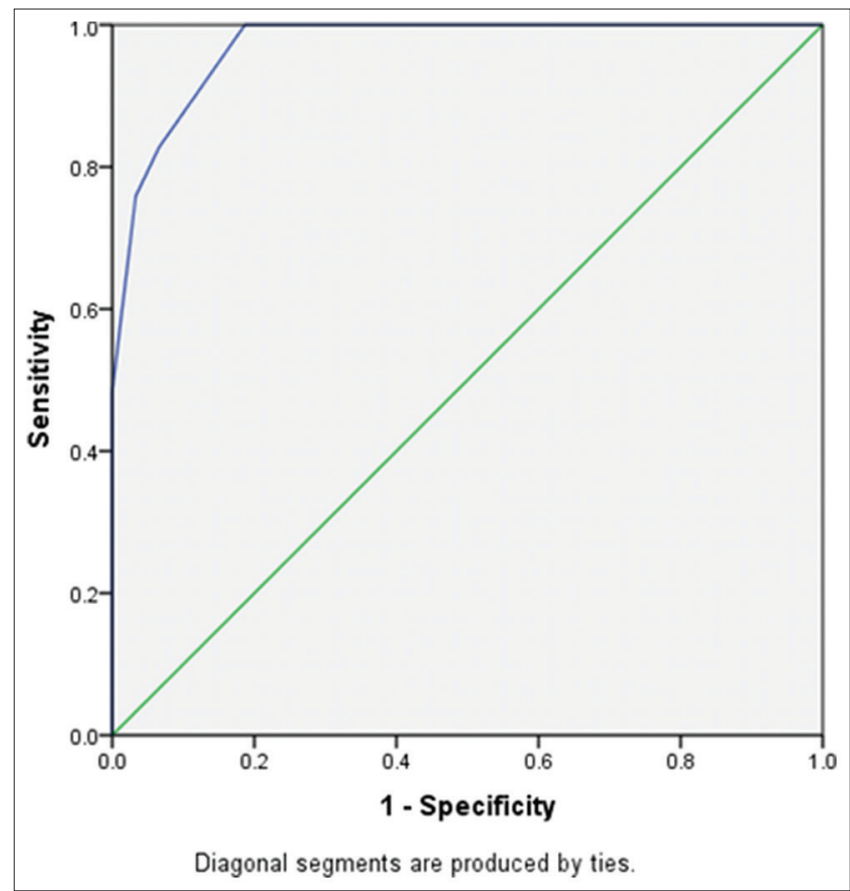

Figure 2: The receiver operating characteristic of the predictive value of portal venous pressure

cutoff value of $\geq 10.5 \mathrm{mmHg}$, the PVP had a sensitivity of $82.8 \%$ and specificity of $93.4 \%$ for the prediction of mortality. The logistic regression analysis showed that only PVP (odds ratio [OR] $=3.1,95 \%$ confidence interval $[\mathrm{Cl}] 1.25-7.5)$ and CVP $(\mathrm{OR}=2.8,95 \% \mathrm{Cl}$ $1.2-6.5)$ were the only independent predictors of death. 


\section{Discussion}

Recently, PVP was reported to be an independent risk factor of death in cirrhotic cases undergoing emergency surgery [16]; however, its predictive utility in the setting of elective surgical interventions in patients with early cirrhosis is still questionable.

In the present study, we found that PVP yielded an acceptable diagnostic accuracy for the prediction of mortality in Child's A cirrhotic patients, a PVP level $\geq 10.5 \mathrm{mmHg}$ exhibited a sensitivity of $82.8 \%$ and specificity of $93.4 \%$ for the prediction of mortality. Besides, this report showed that BMI and CVP were associated with death with high statistical significance. The logistic regression analysis showed that PVP and CVP were independent predictors of mortality.

The currently published body of evidence shows that different surgical procedures are linked to a high risk of adverse outcomes in cirrhotic cases, mainly as a result of hyperdynamic circulation and hepatic hypoxemia [22]. The risk of post-operative mortality was reported to be significantly correlated with the degree of liver diseases; therefore, higher PVP can potentially reflect the increased risk of mortality as the progression of fibrosis parallels the increase in portal pressure [23]. The present study showed that PVP was an independent risk factor of early death. Recently, Salman et al. [16] found that portal hypertension is a significant predictor of the 30-day post-operative death in Child's Class A-C cirrhotic cases submitted to emergency procedures, the PVP yielded high sensitivity (83.6\%) and specificity (92\%). Similarly, Nguyen et al. [24] found that the mortality rate was significantly higher in cirrhotic cases with elevated portal pressure undergoing elective colorectal surgery, in comparison with cases with normal PVP. Given this significant impact of high PVP on the outcomes of surgery in cirrhotic patients, the previous reports suggested that portal decompression by transjugular intrahepatic portosystemic shunt (TIPS) can potentially improve the survival in cirrhotic patients [25]. Kim et al. [26] reported that cirrhotic patients, who underwent TIPS before major surgery, had a lower rate of short-term mortality than previously published reports on patients who did not undergo TIPS.

The MELD score is a risk stratification model for cirrhotic patients that recently exhibited high predictive utility for perioperative mortality [27]. The MELD score is characterized by its objective measures and weights of its variables, which can potentially increase its precision for the prediction of 30-day post-operative mortality in cirrhotic patients [28]. In the current work, we demonstrated that non-survivors were more likely to have a MELD score between 9 and 16 than survivors. In concordance with our findings, Hemida et al. [29] showed that the MELD score had high sensitivity (100\%) and moderate specificity (64\%) for the prediction of death in cirrhotic cases submitted to non-hepatic procedures. Another retrospective study demonstrated that MELD score was associated with 90-day mortality following emergency surgery in patients with cirrhosis [30].

To the best of our knowledge, no or very limited data in the literature have addressed the issue of measuring PVP in Child's A cirrhosis undergoing elective surgery, and so we think that this may be a novel field of research. Even in the present study, we found a cutoff value for PVP readings that could increase post-operative mortality and seem to have acceptable sensitivity and specificity. Expecting patients who are at a high risk of mortality will encourage us to be very cautious regarding these patients and their post-operative care and so may improve the outcome in such patient category through their strict post-operative management and from this point, come the suggested importance and novelty of this research.

Despite this, we claim that this work has some limitations. The work was a single-center experience that may impact the generalizability of our results. Furthermore, more studies on a larger number of patients and unified types of surgical procedures are required for objective validation of results.

\section{Conclusion}

I.O measurement of PVP is a feasible and simple procedure that can predict the short-term mortality in Child's A cirrhotic patients undergoing elective surgery. PVP exhibited an acceptable diagnostic utility for mortality and was an independent predictor of 30-day mortality. Nevertheless, further studies are still warranted to underline our findings due to the currently limited number of published literature.

\section{References}

1. Nusrat S, Khan MS, Fazili J, Madhoun MF. Cirrhosis and its complications: Evidence based treatment. World J Gastroenterol. 2014;20(18):5442-60.

PMid:24833875

2. Murray CJL, Vos T, Lozano R, Naghavi M, Flaxman AD, Michaud C, et al. Disability-adjusted life years (DALYs) for 291 diseases and injuries in 21 regions, 1990-2010:Asystematic analysis for the global burden of disease study 2010. Lancet. 2012;380(9859):2197-223. https://doi.org/10.1016/s0140-6736(12)61690-0 PMid:23245608

3. Mokdad AA, Lopez AD, Shahraz S, Lozano R, Mokdad AH, Stanaway $\mathrm{J}$, et al. Liver cirrhosis mortality in 187 countries between 1980 and 2010: A systematic analysis. BMC Med. 2014;12:145. https://doi.org/10.1186/s12916-014-0145-y 


\section{PMid:25242656}

4. Wiegand J, Berg T. The etiology, diagnosis and prevention of liver cirrhosis: Part 1 of a series on liver cirrhosis. Dtsch Arztebl Int. 2013;110(6):85-91. https://doi.org/10.3238/arztebl.2013.0085 PMid:23451000

5. Heidelbaugh JJ, Sherbondy M. Cirrhosis and chronic liver failure: Part II. Complications and treatment. Am Fam Physician. 2006;74(5):767-76.

PMid:16970020

6. Estes C, Razavi H, Loomba R, Younossi Z, Sanyal AJ. Modeling the epidemic of nonalcoholic fatty liver disease demonstrates an exponential increase in burden of disease. Hepatology. 2018;67(1):123-33. https://doi.org/10.1002/hep.29466 PMid:28802062

7. Demetriades D, Constantinou C, Salim A, Velmahos G, Rhee P, Chan L. Liver cirrhosis in patients undergoing laparotomy for trauma: Effect on outcomes. J Am Coll Surg. 2004;199(4):53842. https://doi.org/10.1016/j.jamcollsurg.2004.06.017 PMid:15454135

8. Millwala F, Nguyen GC, Thuluvath PJ. Outcomes of patients with cirrhosis undergoing non-hepatic surgery: Risk assessment and management. World J Gastroenterol. 2007;13(30):4056-63. https://doi.org/10.3748/wjg.v13.i30.4056

PMid:17696222

9. Keegan MT, Plevak DJ. Preoperative assessment of the patient with liver disease. Am J Gastroenterol. 2005;100(9):2116-27. PMid:16128958

10. Ziser A, Plevak DJ. Morbidity and mortality in cirrhotic patients undergoing anesthesia and surgery. Curr Opin Anesthesiol. 2001;14(6):707-11.

11. Northup PG, Wanamaker RC, Lee VD, Adams RB, Berg CL. Mode for end-stage liver disease (MELD) predicts nontransplant surgical mortality in patients with cirrhosis. Ann Surg. 2005;242(2):244-51. https://doi.org/10.1097/01.sla.0000171327.29262.e0 PMid:16041215

12. Kumar A, Sharma $P$, Sarin SK. Hepatic venous pressure gradient measurement: Time to learn! Indian J Gastroenterol. 2008;27(2):74-80.

PMid:18695309

13. Elbarbary A, Elbedewy M, Elbadry A. Hemodynamic analysis of portal hypertension in patients with liver cirrhosis. Tanta Med J. 2014;42(4):130. https://doi.org/10.4103/1110-1415.145276

14. Kanematsu T, Furui J, Yanaga K, Okudaira S, Kamohara Y, Eguch S. Measurement of portal venous pressure is useful for selecting the optimal type of resection in cirrhotic patients with hepatocellular carcinoma. Hepatogastroenterology. 52(66):1828-31.

PMid:16334786

15. Patch D, Armonis A, Sabin C, Christopoulou K, Greenslade L, McCormick A, et al. Single portal pressure measurement predicts survival in cirrhotic patients with recent bleeding. Gut. 1999;44(2):264-9. https://doi.org/10.1136/gut.44.2.264 PMid:9895388

16. Salman MA, Mansour DA, Balamoun HA, Elbarmelgi MY, Hadad KE, Abo Taleb ME, et al. Portal venous pressure as a predictor of mortality in cirrhotic patients undergoing emergency surgery. Asian J Surg. 2019;42(1):338-42. https:// doi.org/10.1016/j.asjsur.2018.09.007

PMid:30316666

17. Elm E Von, Altman DG, Egger M, Pocock SJ, Gøtzsche PC, Vandenbroucke JP, et al. The Strengthening the reporting of observational studies in epidemiology (STROBE) statement: Guidelines for reporting observational studies. Int J Surg. 2014;12(12):1495-9. https://doi.org/10.1016/j.ijsu.2014.07.013 PMid:25046131
18. Nuttall FQ. Body mass index: Obesity, BMI, and health: A critical review. Nutr Today. 2015; 50(3):117-28. PMid:27340299

19. Williams B, Mancia G, Spiering W, Rosei EA, Azizi M, Burnier M et al. $2018 \mathrm{ESC} / \mathrm{ESH}$ guidelines for the management of arterial hypertension. Eur Heart J. 2018;39(33):3021-104. https://doi. org/10.2337/dc11-s011 PMid:30165516

20. Williams B, Mancia G, Spiering W, Agabiti Rosei E, Azizi M, Burnier M, et al. 2018 ESC/ESH Guidelines for the management of arterial hypertension: The task force for the management of arterial hypertension of the European society of cardiology and the European society of hypertension: The task force for the management of arterial hypertension of the European society of cardiology and the European society of hypertension. J Hypertens. 2018;36(10):1953-2041. https://doi.org/10.1201/b17072-61 PMid:30234752

21. Xu G, Li F, Mao Y. Portal pressure monitoring-state-of-the-art and future perspective. Ann Transl Med. 2019;7(20):583. https:// doi.org/10.21037/atm.2019.09.22 PMid:31807564

22. Friedman LS. Surgery in the patient with liver disease. Trans Am Clin Climatol Assoc. 2010;121:192-204 PMid:20697561

23. Rai R, Nagral S, Nagral A. Surgery in a patient with liver disease. $\mathrm{J}$ Clin Exp Hepatol. 2012;2(3):238-46 PMid:25755440

24. Nguyen GC, Correia AJ, Thuluvath PJ. The impact of cirrhosis and portal hypertension on mortality following colorectal surgery: A nationwide, population-based study. Dis Colon Rectum. 2009;52(8):1367-74. https://doi.org/10.1007/ dcr.0b013e3181a80dca PMid:19617746

25. Gil A, Martínez-Regueira F, Hernández-Lizoain JL, Pardo F, Olea JM, Bastarrika G, et al. The role of transjugular intrahepatic portosystemic shunt prior to abdominal tumoral surgery in cirrhotic patients with portal hypertension. Eur J Surg Oncol. 2004;30(1):46-52. https://doi.org/10.1016/j.ejso.2003.10.014 PMid:14736522

26. Kim JJ, Dasika NL, Yu E, Fontana RJ. Cirrhotic patients with a transjugular intrahepatic portosystemic shunt undergoing major extrahepatic surgery. J Clin Gastroenterol. 2009;43(6):574-9. https://doi.org/10.1097/mcg.0b013e31818738ef

PMid:19169145

27. Malinchoc M, Kamath PS, Gordon FD, Peine CJ, Rank J, Ter Borg PC. A model to predict poor survival in patients undergoing transjugular intrahepatic portosystemic shunts. Hepatology. 2000;31(4):864-71. https://doi.org/10.1053/he.2000.5852 PMid:10733541

28. O'Leary JG, Friedman LS. Predicting surgical risk in patients with cirrhosis:Fromarttoscience. Gastroenterology. 2007;132(4):160911. https://doi.org/10.1053/j.gastro.2007.03.016 PMid:17428482

29. Hemida K, Al Swaff RE, Shabana SS, Said H, Ali-Eldin F. Prediction of post-operative mortality in patients with HCVrelated cirrhosis undergoing non-hepatic surgeries. J Clin Diagn Res. 2016;10(10):OC18-21. https://doi.org/10.7860/ jcdr/2016/22478.8620

PMid:27891371

30. Havens JM, Columbus AB, Olufajo OA, Askari R, Salim A, Christopher KB. Association of model for end-stage liver disease score with mortality in emergency general surgery patients. JAMA Surg. 2016;151(7):e160789. https://doi.org/10.1001/ jamasurg.2016.0789

PMid:27192189 